\title{
Seleção de caminho baseada em atraso para sistemas multi-abrigados usando SCTP
}

\author{
Igor Gavriloff e Eduardo P. Ribeiro
}

\begin{abstract}
Resumo-Este artigo avalia o desempenho da seleção de rota em sistemas multi-abrigados usando SCTP como protocolo de transporte para tráfegos multimídia. O mecanismo de seleção de rotas foi implementado no simulador de redes NS-2. A avaliação do desempenho deste mecanismo dá-se por uma métrica derivada de uma recomendação do ITU-T.
\end{abstract}

Palavras-Chave-SCTP, multi-abrigado, atraso, NS-2.

Abstract-This article evaluates the route selection performance in multihomed systems using SCTP as the transport protocol for multimedia traffic. The route selection mechanism was implemented using the NS-2 network simulator. The performance evaluation is given by a metric derived from a ITU-T recomendation.

Keywords-SCTP, multihomed, delay, NS-2.

\section{INTRODUÇÃo}

A popularização e diminuição dos custos de conexão com a Internet tem facilitado a possibilidade de conexão de usuários finais a mais de um provedor de serviço de Internet (PSI). Inicialmente esta modalidade traz benefícios de resiliência pois quando uma conexão apresenta falha os dados podem fluir pelo canal alternativo. Porém, permite também um novo cenário para a melhoria do desempenho da comunicação com a devida escolha do melhor caminho para transmissão. Quando ambos os usuários finais estão conectados a mais de um PSI, ou multi-abrigados (multi-homed), a possibilidade da diversificação de caminhos pode aumentar ainda mais. O aumento de opções de acesso sem fio também vem contribuir para o incremento de possibilidades de conexão. Sistemas fixos ou móveis podem estar conectados à mais de uma antena de diferentes provedores de acesso sob diferentes tecnologias: WiFi, WiMAX, UWB, UMTS, e várias outras que constituem a nova realidade de redes heterogêneas.

A maneira tradicional de se utilizar mais de uma faixa de endereços IP envolve o protocolo BGP (Border Gateway Protocol) [1] para informar aos roteadores vizinhos (e por sua vez a toda rede mundial) como a rede em questão pode ser atingida. O problema principal desta alternativa é a falta de escalabilidade desta solução para atender um número grande de sistemas finais. Normalmente apenas grandes faixa de endereços são anunciadas [2].

Recentemente algumas alternativas têm sido propostas para a lidar com esta característica dos sistemas multi-abrigados [3]. Deseja-se um mecanismo escalável que possa atender não apenas as grandes corporações mas também os usuários

Igor Gavriloff e Eduardo P. Ribeiro Departamento de Engenharia Elétrica, Universidade Federal do Paraná, Curitiba, PR, Brasil, E-mails: igor@wisehelp.com.br, edu@eletrica.ufpr.br. médios e pequenos que não dispõem de BGP. Uma dessas promissoras soluções envolve a utilização do SCTP como protocolo de transporte (camada 4), o que torna a solução independente dos protocolos de roteamento (camada 3).

Neste trabalho a estratégia de seleção de caminho baseada apenas no atraso fim-a-fim estimado no protocolo SCTP foi considerada. Imagina-que se esta estratégia seja bastante adequada ao transporte de fluxos multimídia em tempo-real pois tais aplicações são bastante sensíveis ao atraso. Além disso, ao contrário de uma transmissão volumosa de arquivo de dados, a maioria das transmissões multimídia, principalmente no caso de voz, não representam um volume grande de dados competindo por largura de banda mas uma transmissão cadenciada de baixa taxa. Usualmente são transportadas pelo protocolo UDP (User Datagram Protocol) e geralmente com auxílio do RTP (Real Time Protocol).

A seguir é feita uma breve descrição do SCTP. Na seção seguinte os trabalhos relacionados são comentados. A seção IV descreve a metodologia usada neste trabalho e os resultados são apresentados na seção V. As conclusões são apresentadas na seção VI.

\section{SCTP}

O protocolo SCTP foi criado inicialmente para permitir o transportes de múltiplos fluxos (streams) em uma mesma sessão [4]. Desta maneira pode-se, por exemplo, transportar informações de controle e sinalização juntamente com o tráfego de voz. O SCTP também estabeleceu uma boa base para a operação de sistemas multi-abrigados. Por exemplo, se dois sistemas possuem duas e três conexões com a Internet respectivamente com os endereços IP1, IP2, IP3 e IP4, IP5, então no início da sessão é estabelecida uma associação:

associação $=\{[$ IIP1,IP2,IP3: Porta A $] ;[$ IP4,IP5: Porta B $]\}$

Cada lado possui seu número de porta. Os dados podem então fluir pelo endereço primário (no exemplo IP1 e IP4). Em caso de falha deste caminho primário um caminho secundário é automaticamente selecionado (IP2,IP5) mantendo a mesma sessão. De tempos em tempos o protocolo manda pacotes chamados pulsação (heartbeats) para os caminhos secundários para verificar se eles ainda estão ativos e disponíveis para serem utilizados caso o caminho primário venha a falhar. $\mathrm{O}$ intervalo padrão do protocolo para envio dos heartbeats é de 30 s.

Originalmente os endereços participantes da associação eram estabelecidos durante a abertura da conexão, porém extensões do protocolo permitem a adição e remoção de endereços de forma dinâmica durante a sessão. Isto torna 
o protocolo bastante adequado para operação no ambiente móvel [5]. Outra extensão, particularmente importante para a transmissão de dados multimídia em tempo real, introduziu o conceito de confiabilidade parcial [6]. Neste modo de operação os pacotes não precisam ser retransmitidos de forma semelhante ao UDP. A aplicação pode determinar a nível do fluxo ou do pacote qual o tempo limite no qual o pacote ainda deve ser retransmitido.

\section{Trabalhos Relacionados}

Vários trabalhos têm apresentado o SCTP como uma boa solução para clientes móveis [5][7]. O processo de comutação (handover) pode ser decidido pelo cliente baseado em informações como intensidade do sinal e nível de bateria.

O uso da medida do atraso para seleção do caminho já vem sendo proposta há algum tempo [8][9]. Porém com o advento do SCTP esta alternativa se torna ainda mais atraente. Um interessante esquema de comutação baseado em atraso (delay) foi anteriormente proposto para redes locais sem fio [10]. Alguns estudos preliminares indicam que esse mecanismo pode ser bastante vantajoso para o transporte de tráfego multimídia principlamente num cenário móvel sem fio [11].

No presente trabalho é feita uma avaliação de desempenho do mecanismo de seleção de rota num cenário simulado com uma métrica que reflete a qualidade da percepção da voz. Analisou-se também o efeito do parâmetro de histerese que impede uma mudança imediata de caminho.

\section{Metodologia}

Os testes foram realizados utilizando o simulador de redes NS-2. Este software escrito em $\mathrm{C}++$ possui ligação com um interpretador Tcl. As classes escritas em $\mathrm{C}++$ podem ser manipuladas por scripts $\mathrm{Tcl}$ proporcionando desempenho $\mathrm{e}$ versatilidade. A classe $\mathrm{C}++$ do agente SCTP disponível no NS-2 foi extendida de forma que fosse possível repassar ao código Tcl a informação da atualização dos tempos de ida e volta suavizados (Smoothed Round Trip Time - SRTT) do SCTP. Nenhuma outra alteração no agente SCTP, seja no comportamento ou criando um novo tipo de trecho (chunk), foi realizada. Apenas diferentes valores para o intervalo da pulsação (heartbeat) foram utilizados. O script Tcl é responsável por comandar a mudança de rota no agente SCTP escolhendo a rota com menor estimativa de atraso. Para esta estimativa foi utilizado o SRTT que já é normalmente computado pelo SCTP quando recebe as confirmações dos pacotes de dados ou as pulsações. Para realizar a decisão de mudança de rota baseado nesta estimativa de atraso adicionouse ainda um parâmetro de limiar para introduzir uma histerese se diferente de zero. O mecanismo de troca de rota nativo do SCTP por limiar de erros não teve efeito pois tomou-se cuidado para que não houvesse descarte de pacotes em trânsito.

A topologia considerada apresenta dois agentes SCTP entre os quais é realizada a comunicação. Para os ensaios apresentados neste artigo foi empregado um gerador de tráfego CBR com parâmetros tais que simule um tráfego de voz usando o codificador de voz (codec) G.711[12] sem supressão de silêncio: cada pacote transporta 160 bytes do codificador de voz à uma taxa de 64kbps. Levando em consideração a carga extra (overhead) do SCTP a taxa final será de aproximadamente 80kbps. Fez-se uso da extensão de confiabilidade parcial: pacotes perdidos são apenas reportados mas não retransmitidos.

Existem duas rotas distintas que não compartilham nenhum enlace de gargalo. Cada uma destas rotas possui quatro nós: os dois nós das extremidades encontram-se conectados aos agentes SCTP (e são considerados parte dos sistemas finais) enquanto que os dois nós centrais são usados para conectar agentes com aplicações geradoras de tráfego de forma a haver um tráfego de fundo que possa ser controlado. Estas aplicações de tráfego são tais que se assemelham à um conjunto de diversas fontes provindos de diferentes nós causando um atraso que estatisticamente assemelha-se ao que supõe-se encontrar em redes núcleos (core).

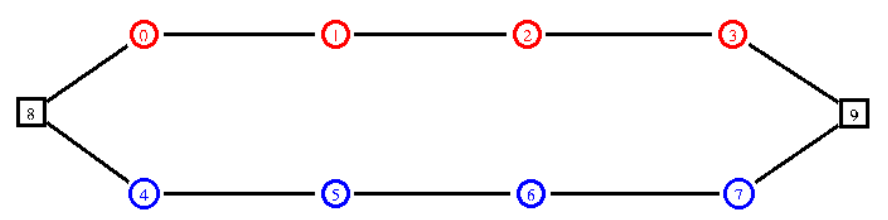

Fig. 1. Topologia da rede usada no simulador. Os nós 8 e 9 são os nós multi-abrigados do SCTP. Os agentes das aplicações geradoras de tráfego estão conectadas diretamente aos nós centrais e não estão representados na figura.

O gerador de tráfego de fundo consiste em aplicações geradoras de conteúdo com tamanho do pacote fixo e intervalo de chegada entre pacotes dado por uma distribuição exponencial seguindo um processo de Markov. Um gerador de tráfego com distribuição exponencial está implementado no NS-2 na clase denominada Application/Traffic/Exponential. Esta classe gera um tráfego do tipo ligado-desligado $(O N-O F F)$, tendo como parâmetros de entrada a taxa do tráfego durante uma rajada (burst), o tempo médio da rajada $\left(t_{o n}\right)$ e o tempo médio de ocioso $\left(t_{o f f}\right)$. Os intervalos de tempo de ligado e de desligado são aleatórios dados por uma distribuição exponencial.

Para empregar os modelos de fila M/D/1 (notação de Kendall para filas com tempo de chegada Markoviano e tempo de serviço constante com um único enlace de saída) os parâmetros deste gerador foram cuidadosamente escolhidos para funcionar seguindo um processo de Markov [13]. O tempo de rajada é especificado como zero o que força a geração de apenas um único pacote de tamanho $(L) 1000$ bytes no intervalo de ligado. Apesar da taxa da rajada estar sendo ignorada, pois apenas um pacote é gerado nas rajadas, o valor atribuído foi de $100 \mathrm{Gbps}$ para efeito de cálculo: pode-se considerar que

$$
t_{\text {on }}<<t_{\text {off }}
$$

uma vez que o intervalo de desligado é algumas magnitudes maior do que o intervalo de ligado teórico dado pela taxa de rajada. Em uma simplificação para estimar uma taxa média de chegada de pacotes na fila $(\lambda)$ apenas o tamanho do pacote e o intervalo médio do intervalo desligado é levado em conta pois o intervalo de ligado pode ser desprezado: 


$$
\lambda=\frac{L}{t_{o f f}}
$$

O fator de utilização é a razão do somatório da taxa média de chegada de pacotes pela taxa de vazão nominal $B$ do enlace. O somatório é possível pois a taxa média de um conjunto de processos de Markov pode ser visto como a soma da média destes processos. Nas simulações foram consideradas 5 fontes.

$$
\rho=\frac{\sum \lambda}{B}
$$

Com este gerador é possível fazer o emprego do modelo de fila M/D/1 para relacionar o tamanho médio da fila $(\bar{q})$ com o fator de utilização do enlace $(\rho)$ [14].

$$
\bar{q}=\frac{\rho}{1-\rho}-\frac{\rho^{2}}{2(1-\rho)}
$$

Para que o enlace de gargalo apresente um determinado atraso basta determinar qual o tamanho médio da fila necessário para causar tal atraso para determinar o fator de utilização necessário para então determinar o intervalo médio a ser especificado no gerador de tráfego de fundo.

Os fatores de utilização e os atrasos em cada uma das rotas empregados nas simulações foram escolhidos de tal forma que houvesse momentos em que uma rota ora estivesse com atraso menor, maior ou igual ao da outra rota. Uma vez que o atraso causado pelos geradores de tráfego está diretamente ligado ao fator de utilização do canal, os valores escolhidos são tais que não causam uma situação de quase saturação dos enlaces, evitando o descarte de pacotes que estejam em trânsito. Os valores empregados nos geradores de tráfego de fundo de cada rota ao decorrer da simulação estão listados na tabela I.

TABELA I

FATOR DE UTILIZAÇÃo E ATRASO MÉDIO ESTIMADO NAS ROTAS CAUSADOS PELOS GERADORES DE TRÁFEGO DE FUNDO

\begin{tabular}{c|c|c|c}
\hline Rota & Intervalo [s] & Fator de utilização [\%] & Atraso estimado [ms] \\
\hline \hline \multirow{3}{*}{ Rota 0 0} & {$[0 . .50)$} & 72 & 8 \\
\cline { 2 - 4 } & {$[50 \ldots 150)$} & 87 & 40 \\
\cline { 2 - 4 } & {$[150 . .250)$} & 78 & 16 \\
\hline \multirow{3}{*}{ Rota 1 } & {$[0 . .100)$} & 72 & 16 \\
\cline { 2 - 4 } & {$[100 \ldots 200)$} & 86 & 40 \\
\cline { 2 - 4 } & {$[200 \ldots 250)$} & 92 & 80 \\
\hline
\end{tabular}

A base da métrica de desempenho levada em consideração foi o atraso dado pelo intervalo de tempo desde o instante em que o som é pronunciada pelo usuário na origem até o momento da percepção do som pelo usuário no destino[15]. A taxa de transferência (throughput) não é de interesse nesta análise pois o tráfego de voz é constante (CBR). Apesar de existir uma relação direta entre este dois parâmetros por o atraso ser proporcional ao fator de utilização da rota, supõese a influência do tráfego de voz ser menor que o tráfego de fundo.

\section{Resultados}

As simulações foram realizadas em dois cenários. Em ambos os cenários a mesma topologia de rede foi utilizada: os nós, características dos enlaces e filas e taxas de ocupação dos enlaces são idênticos. O que diferencia os dois cenários é que em um cenário as duas rotas disponíveis são utilizadas de acordo com o critério de menor SRTT medido enquanto que no outro cenário a utilização das rotas não sofre alteração: o mecanismo de seleção não é utilizado. A finalidade de não se utilizar o mecanismo de seleção em um dos cenários é de haver uma referência para as métricas adotadas. Outros protocolos de transporte como UDP e TCP não possuem funcionalidade na pilha para lidar com sistemas multi-abrigados e teriam comportamento similar ao SCTP sem o mecanismo de seleção de rota. No cenário em que o mecanismo de seleção é utilizado, fez-se ainda experimentos com alguns valores de histerese na decisão da seleção de rota.

Presume-se que para compensar a variação de latência (jitter) o receptor tenha um buffer anti-jitter suficientemente grande que atende todos os casos simulados. Em uma préanálise, analisando-se os resultados de todas as simulações, escolheu-se o valor de $20 \mathrm{~ms}$ para o buffer anti-jitter. Para um buffer deste tamanho estima-se que este cause um atraso médio de $10 \mathrm{~ms}$ no fluxo de dados [16]. O codificador de voz também contribui para o atraso. No caso do G.711 com dois frames por pacote o atraso causado pelo codificador de voz é $0,625 \mathrm{~ms}$ [15].

Para avaliar o desempenho do mecanismo de seleção adotou-se a métrica da razão dos pacotes com atraso menor à um limiar em relação à quantidade total de pacotes transmitidos. A norma ITU-T Y.1541 [15] estabelece como objetivo o valor de $100 \mathrm{~ms}$ para um atraso desde o instante em que o som é pronunciado na origem até o instante que ela é percebida pelo usuário remoto. Levando em consideração o atraso médio causado pelo buffer anti-jitter e ainda também do atraso causado pelo codificador de voz, para assegurar o cumprimento do objetivo o atraso tolerável do trânsito dos pacotes na rede é de 89,375ms. Existem outros fatores nos terminais que contribuem no atraso - tal como o processamento da pilha (stack) TCP/IP - que não estão sendo levados em consideração para simplificar a análise.

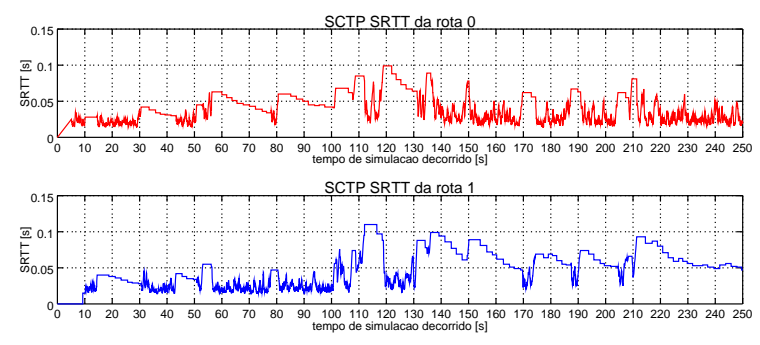

Fig. 2. SRTT medido pelo agente SCTP em cada uma das rotas disponíveis

A figura 2 mostra as flutuações dos SRTT medidos no decorrer da simulação em cada uma das rotas para o caso com histerese em 10ms com o mecanismo de seleção de rota atuando. Contudo uma vez que o mecanismo de seleção está atuando, apenas uma das rotas será utilizada em um dado momento.

$\mathrm{O}$ atraso percebido pela aplicação no agente recebendo os pacotes é devido a apenas uma das rotas: a figura 3 mostra o 


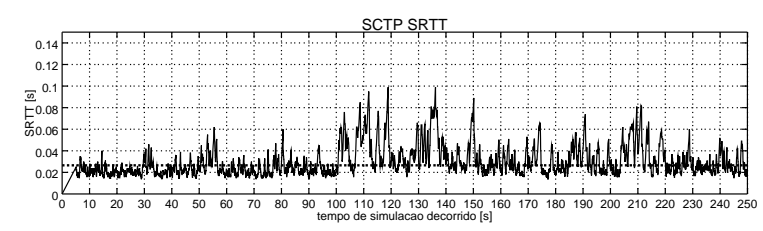

Fig. 3. SRTT medido pelo agente SCTP visto apenas pela rota ativa

SRTT medido levando em consideração apenas a rota ativa. É a partir desta análise em que o atraso da rota ativa é considerada que se aplica a métrica do limiar do atraso para avaliar o desempenho do sistema.

Devido à natureza aleatória do gerador de tráfego de fundo a variação instantânea da latência apresenta um comportamento aleatório. Um caso típico da variação da latência pode ser visualizado na figura 4. No entanto de acordo com a recomendação do ITU[17] a variação da latência deve ser a diferença do instante em que o pacote deveria ter chegado em relação à um instante de referência. Esta referência é uma média do atraso dos pacotes recebidos, tornando então suavizada a percepção da variação da latência.

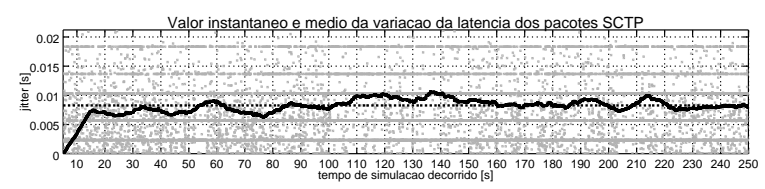

Fig. 4. Variação da latência instantânea e média dos pacotes SCTP de voz com histerese de $10 \mathrm{~ms}$ - valor médio global em pontilhado

Nas figuras citadas anteriormente é difícil visualizar com precisão em quais momentos as rotas eram escolhidas como ativas. Na figura 5 é possível distinguir quais rotas foram selecionadas nos diferentes intervalos observando-se a utilização de banda de cada rota pelo agente SCTP.
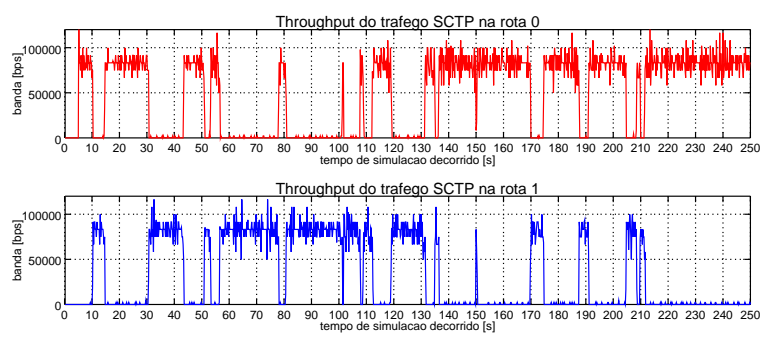

Fig. 5. Taxa de utilização de banda nas rotas pelo tráfego de voz

A tabela II exibe o valor médio e o desvio padrão da variação da latência medidos em cenários com diferentes valores para a histerese do mecanismo de seleção de rota. É interessante observar que a histerese praticamente não altera os valores.

No entanto, na tabela III vê-se que a histerese influencia fortemente a quantidade de trocas de rotas realizadas pelo mecanismo de seleção. Esta a tabela mostra o número de troca de rotas ocorrida em cada simulação para os mesmos valores de histerese. Não existem valores de quantidade de troca de
TABELA II

COMPARATIVO DA VARIAÇÃO DE LATÊNCIA NOS PACOTES DE VOZ

\begin{tabular}{|c|c|c|c|}
\hline Rota & Histerese [ms] & Medida & Valores [ms] \\
\hline \multirow{8}{*}{ Variável } & \multirow{2}{*}{0} & média & 8.2 \\
\hline & & desvio & 7.8 \\
\hline & \multirow{2}{*}{10} & média & 8.2 \\
\hline & & desvio & 7.9 \\
\hline & \multirow{2}{*}{20} & média & 8.1 \\
\hline & & desvio & 7.4 \\
\hline & \multirow{2}{*}{30} & média & 8.1 \\
\hline & & desvio & 7.6 \\
\hline \multirow[b]{2}{*}{ Rota 0} & \multirow{2}{*}{-} & média & 8.3 \\
\hline & & desvio & 6.8 \\
\hline \multirow[b]{2}{*}{ Rota 1} & \multirow{2}{*}{-} & média & 8.6 \\
\hline & & desvio & 6.8 \\
\hline
\end{tabular}

rotas para os casos em que o mecanismo de seleçao não está atuando por não haver a possibilidade de troca de rotas nestes cenários.

TABELA III

HisTERESE E QUANTIDADE DE TROCAS DE ROTA

\begin{tabular}{c|c}
\hline Histerese $[\mathrm{ms}]$ & Trocas \\
\hline \hline 0 & 56 \\
\hline 10 & 28 \\
\hline 20 & 14 \\
\hline 30 & 10 \\
\hline
\end{tabular}

Os valores médios e desvios padrões dos atrasos dados pelo tempo em que os pacotes estiveram efetivamente em trânsito (e não pelo SRTT) para cada um dos cenários estão listados na tabela IV. Uma vez que a métrica do limiar é fruto do atraso de cada pacote individual, nesta tabela já é possível ter uma noção do desempenho do sistema. Novamente a histerese não apresenta uma forte influência nos resultados.

TABELA IV

COMPARATIVO DO ATRASO NOS PACOTES DE VOZ

\begin{tabular}{|c|c|c|c|}
\hline Rota & Histerese [ms] & Medida & Valores [ms] \\
\hline \multirow{12}{*}{ Variável } & \multirow{3}{*}{0} & média & 28 \\
\hline & & desvio & 27 \\
\hline & & máximo & 238 \\
\hline & \multirow{3}{*}{10} & média & 30 \\
\hline & & desvio & 31 \\
\hline & & máximo & 280 \\
\hline & \multirow{3}{*}{20} & média & 30 \\
\hline & & desvio & 30 \\
\hline & & máximo & 280 \\
\hline & \multirow{3}{*}{30} & média & 31 \\
\hline & & desvio & 35 \\
\hline & & máximo & 305 \\
\hline \multirow{3}{*}{ Rota 0} & \multirow{3}{*}{-} & média & 40 \\
\hline & & desvio & 41 \\
\hline & & máximo & 255 \\
\hline \multirow{3}{*}{ Rota 1} & \multirow{3}{*}{-} & média & 91 \\
\hline & & desvio & 123 \\
\hline & & máximo & 638 \\
\hline
\end{tabular}

O foco deste trabalho é a análise sob a ótica de uma métrica que reflete a qualidade percebida da voz e a tabela $\mathrm{V}$ lista para cada simulação o valor resultante desta métrica. Como esta métrica está diretamente relacionada com o atraso, era de se esperar que assim como ocorreu com o atraso a histerese também não exercesse uma influência significativa 
nos valores da métrica. $\mathrm{O}$ fator que influencia fortemente a variação do desempenho da métrica por limiar do atraso é a atuação do mecanismo de seleção de rota: o ganho varia de aproximadamente $6 \%$ (pior caso) a $37 \%$ (melhor caso) entre os cenários analisados (tabela V).

TABELA V

RAZÃO DOS PACOTES QUE CUMPRIMEM O LIMIAR DE ATRASO EM RELAÇÃO À QUANTIDADE TOTAL DE PACOTES

\begin{tabular}{c|c|c}
\hline Rota & Histerese [ms] & Razão [\%] \\
\hline \hline \multirow{3}{*}{ Variável } & 0 & 96 \\
\cline { 2 - 3 } & 10 & 94 \\
\cline { 2 - 3 } & 20 & 94 \\
\cline { 2 - 3 } & 30 & 92 \\
\hline Rota 0 & - & 87 \\
\hline Rota 1 & - & 70 \\
\hline
\end{tabular}

Os valores de pico que ocorrem quando o mecanismo de seleção de rota não está agindo possivelmente deve-se à uma sobrecarga do enlace por causa do tráfego que os pacotes de voz agregam quando somadas à rajadas do gerador de tráfego de fundo fazendo com que a quantidade de pacotes nas filas aumente por o fator de utilização ultrapassar o valor unitário e demorem a esvaziar pois o fator de utilização ainda estar próximo à unidade. Este comportamento de sobrecarga é bem visível no gráfico do SRTT (figura 6) para o cenário sem o mecanismo de troca de rotas, refletindo-se também nos valores máximos do atrasos listados na tabela VI nos cenários sem o mecanismo de troca de rotas.

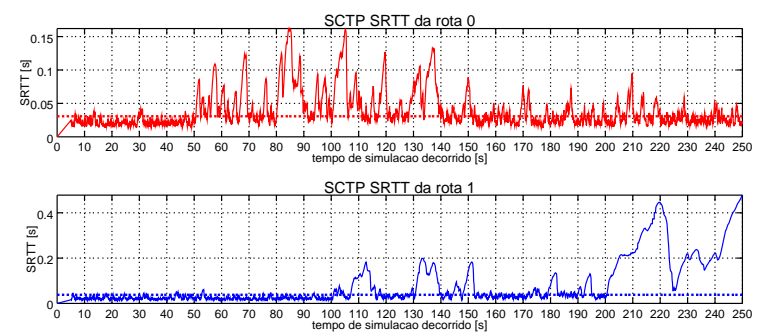

Fig. 6. SRTT nas rotas sem o mecanismo de seleção com geradores tráfego de voz atuando simultaneamente e independentemente - valores médios totais em pontilhado

Esta observação fica reforçada quando as informações encontradas na tabela I são confrontadas com este gráfico: justamente a partir do instante 200s é que a segunda rota apresenta o maior atraso de toda a simulação, instante a partir do qual o gráfico do SRTT apresentou uma sobrecarga das filas também na segunda rota.

\section{Conclusões}

No cenário analisado, onde a taxa de utilização nos dois caminhos é variada para simular diferentes condições de gargalo na rede, o emprego do mecanismo de seleção de rota apresentou melhora no desempenho.

Mostrou-se os potenciais benefícios de se usar o mecanismo para a escolha de caminho em uma comunicação SCTP para tráfego multimídia (de voz) num cenário em que não há
TABELA VI

COMPARATIVO DO SRTT DO TRÁFEGO DE VOZ

\begin{tabular}{|c|c|c|c|}
\hline Rota & Histerese [ms] & Medida & Valores [ms] \\
\hline \multirow{4}{*}{ Variável } & 0 & $\begin{array}{c}\text { média } \\
\text { desvio } \\
\text { máximo }\end{array}$ & $\begin{array}{c}25 \\
9 \\
100\end{array}$ \\
\hline & 10 & $\begin{array}{c}\text { média } \\
\text { desvio } \\
\text { máximo }\end{array}$ & $\begin{array}{l}26 \\
11 \\
99\end{array}$ \\
\hline & 20 & $\begin{array}{c}\text { média } \\
\text { desvio } \\
\text { máximo }\end{array}$ & $\begin{array}{c}26 \\
11 \\
122\end{array}$ \\
\hline & 30 & $\begin{array}{c}\text { média } \\
\text { desvio } \\
\text { máximo }\end{array}$ & $\begin{array}{c}26 \\
12 \\
132 \\
\end{array}$ \\
\hline Rota 0 & - & $\begin{array}{c}\text { média } \\
\text { desvio } \\
\text { máximo }\end{array}$ & $\begin{array}{c}30 \\
18 \\
162\end{array}$ \\
\hline Rota 1 & - & $\begin{array}{c}\text { média } \\
\text { desvio } \\
\text { máximo }\end{array}$ & $\begin{array}{c}38 \\
48 \\
478 \\
\end{array}$ \\
\hline
\end{tabular}

retransmissão de pacotes perdidos ou descartados. Este mecanismo resultou numa melhora da qualidade da informação recebida não apenas por apresentar um atraso menor mas porque que há ganho quando analisado por uma métrica de desempenho baseada na percepção da qualidade para este tráfego de voz em questão. Como objetivo de trabalho futuro pretende-se analisar qual a influência no desempenho do sistema com diferentes taxas de ocupação dos enlaces pelos geradores de tráfego de fundo e quando diversas comunicações SCTP empregam o mesmo mecanismo de mudança de rota.

\section{REFERÊNCIAS}

[1] Y. Rekhter and T. Li, "A border gateway protocol 4 (bgp-4)," RFC1771, 1995.

[2] J. Abley, B. Black, and V. Gill, "Goals for ipv6 site-multihoming architectures," RFC3582, 2003.

[3] C. Launois and M. Bagnulo, "The paths toward ipv6 multihoming," IEEE Communications Survey, vol. 8, no. 2, 2006.

[4] R. Stewart and Q. Xie, Stream control transmission protocol (SCTP): a reference guide. Addison-Wesley Longman Publishing Co., Inc., 2001.

[5] S. J. Koh, M. J. Chang, and M. Lee, "msctp for soft handover in transport layer," IEEE COMMUNICATIONS LETTERS, vol. 8, no. 3, pp. 189-191, 2004.

[6] R. e. a. Stewart, "Stream control transmission protocol (sctp) - partial reliability extension," RFC3758, March 2004.

[7] L. Ma, F. Yu, V. C. M. Leung, and T. S. Randhawa, "A new method to support umts/wlan vertical handover using sctp," IEEE WIRELESS COMMUNICATIONS, vol. 11, no. 4, pp. 44-51, 2004.

[8] N. Yamai, K. Okayama, H. Shimamoto, and T. Okamoto, "A dynamic traffic sharing with minimal administration on multi-homed networks," Proc. IEEE Int. Conf. Commun. (ICC2001), vol. 5, pp. 1506-1510, june 2001.

[9] A. Akella, B. Maggs, S. Seshan, A. Shaikh, and R. Sitaraman, "A measurement-based analysis of multihoming," COMPUTER COMMUNICATION REVIEW, vol. 33, no. 4, pp. 353-364, 2003.

[10] A. Kelly, G. Muntean, P. Perry, and J. Murphy, "Delay-centric handover in sctp over wlan," Transactions on Automatic Control and Computer Science, vol. 49, no. 63, pp. 211-216, 2004.

[11] J. Noonan, P. Perry, S. Murphy, and J. Murphy, "Simulations of multimedia traffic over sctp modified for delay-centric handover," World Wireless Congress, 2004.

[12] "ITU-T recommendation G.711," International Telecommunication Union, Tech. Rep., 1988.

[13] B. Hechenleitner and K. Entacher, "On shortcomings of the ns-2 random number generator," 2002. [Online]. Available: citeseer.ist.psu.edu/article/hechenleitner02shortcomings.html

[14] L. Kleinrock, Queueing Systems. Volume I: Theory. New York: John Wiley \& Sons, 1975. 
XXVI SIMPÓSIO BRASILEIRO DE TELECOMUNICAÇÕES - SBrT’08, 02-05 DE SETEMBRO DE 2008, RIO DE JANEIRO, RJ

[15] “ITU-T recommendation Y.1541," International Telecommunication Union, Tech. Rep., 1993.

[16] "ITU-T recommendation G.114," International Telecommunication Union, Tech. Rep., 1993.

[17] "ITU-T recommendation Y.1540," International Telecommunication Union, Tech. Rep., 1993. 